\title{
The Economics of a Temporary VAT Cut ${ }^{*}$
}

\author{
Thomas Crossley \\ Institute for Fiscal Studies and University of Cambridge \\ Hamish Low \\ Institute for Fiscal Studies and University of Cambridge \\ Matthew Wakefield \\ Institute for Fiscal Studies, University College London and University of Bologna
}

January 2009

\footnotetext{
${ }^{*}$ We thank our colleagues at the Institute for Fiscal Studies, particularly Stuart Adam, Richard Blundell, Carl Emmerson, David Phillips and Ian Preston for helpful comments and discussion. All errors are our own.
} 


\section{Executive Summary}

1. The rate of VAT has been cut temporarily to $15 \%$, with a return to $17.5 \%$ in place for the end of 2009. The government has predicted that this will increase consumer spending by about $0.5 \%$. Much of the analysis of this tax cut has been critical of the policy and concluded that the government's estimates of the impact on spending are over-optimistic. The source of this criticism is a misunderstanding of the mechanism through which the tax cut will have an impact. In fact, we believe the government's estimates are overly-pessimistic.

2. There are two mechanisms through which the temporary VAT cut might affect spending: first, it will increase spending power, making households feel as if they have more income. This mechanism is likely to be small partly because the tax cut increases income only for one year, and so the increase in total lifetime resources is very small, and partly because the lost revenue will have to be paid back.

3. However, the second (often ignored) mechanism is likely to be much more important. This second mechanism is the effect that the tax cut will have through changing the price of goods bought in 2009 compared to 2010: the cost of goods bought in 2009 has fallen compared to goods bought in 2010 and this change in prices gives an incentive to bring forward consumer spending to this year, rather than waiting until next.

4. Economic evidence on households' willingness to move spending from one year into an earlier (or later) year suggests that a $1 \%$ fall in the price today will translate into a $1 \%$ increase in spending. Since roughly only half of goods purchased are subject to VAT, the cut in the rate by $2.5 \%$ is like a cut in prices today by $1.25 \%$ and we would expect this to boost spending by about $1.25 \%$ over what it would otherwise be.

5. Of course, this issue of what the spending would otherwise be is crucial: we will not now know what spending in 2009 would have been without the cut in VAT and even with the VAT cut, spending is likely to decline. Our point is simply that economic analysis shows that the cut in VAT will make the situation significantly less bad than it might otherwise have been.

6. A natural comparison to the fiscal stimulus of a cut in VAT is a monetary stimulus through a cut in the interest rate: both make the price of spending today low compared to next year - an interest rate cut makes saving less attractive than current spending, as does the cut in VAT. The $1.25 \%$ fall in prices due to the cut in VAT reduces the price of spending today by more than a $1 \%$ point cut in the interest rate. It is surprising that some commentators have labeled the former as "small", while the latter would typically be considered a large cut.

7. There is however a difference between cutting interest rates and cutting VAT: a cut in interest rates penalises savers, whose spending power falls, and rewards borrowers. By contrast, the cut in VAT increases the spending power of savers (as well as borrowers) and this seems a fairer way to stimulate the economy. 


\section{The Economics of a Temporary VAT Cut}

The U.K. government has just announced a temporary VAT cut - from $17.5 \%$ to $15 \%$ for 13 months - as an economic stimulus. Similar measures are under discussion in other countries. When formulating its forecasts for the UK macro-economy, the Treasury made the following assumptions:

"With respect to stimulating spending, the forecast assumes that approximately half of the increase in real purchasing power translates into an increased volume of spending, with the remainder used by households to bolster their finances.”

HM Treasury, 2008, paragraph 2.25

We interpret this as saying that: for each one percent reduction in prices that is caused by the policy change, consumption is assumed to increase by half a percent; and the described mechanism through which this change operates is an income effect whereby the reduction in the price level increases the value of resources today and this extra value can be shared between consumption today and future consumption (saving).

In this note we argue that economic analysis strongly supports the view that the response of consumption to price changes due to the temporary VAT cut will be larger than a half a percent increase for each one percent fall in prices; indeed we believe that the response might be approximately one-for-one. A crucial part of our argument is that the response of individuals who do not face binding credit constraints is not driven primarily by an income effect, but rather by a substitution effect due to the impact of the policy on the relative prices of current and future consumption.

We begin by assuming full pass-through - that prices will fall by exactly the amount of the VAT cut. We return to this below. However, note that some goods (food 
and water, passenger transport, the construction of new dwellings, reading materials, children's clothing and prescription drugs, being the most important in terms of expenditure) face a zero-rate of VAT, while home heating fuel and a few other items are charged at a reduced (5\%) rate. Thus a 2.5 percentage point cut in the main rate of VAT does not reduce the price of all consumption today by 2.5 percentage points. About 55\% of (gross) expenditures are on taxable products, which implies that about 51\% of (net) consumption is taxed and an average tax rate of about 8.9 percent. Assuming limited within-period substitution possibilities, full pass-through then leads to a change in the average tax rate of about -1.275 percentage points. Note that this is a $\frac{-1.275 \%}{8.9 \%}=-14.3 \%$ proportional change the tax rate $(t)$, but a much smaller proportional change in the relative price of consumption. This is because, as we shall elaborate below, the latter depends on the proportional change in $(1+t)$. Assuming full pass-through, the proportional change in the relative price of current consumption is $\frac{-1.275 \%}{108.9 \%}=-1.17 \%$ or about $-1.2 \%$.

Assuming this change in the relative price of consumption, we show now the similarities (and differences) between a temporary cut in VAT and a cut in the interest rate. We then discuss the evidence on the likely behavioural consequences of the tax cut, the likely consequences for VAT revenue, and distributional consequences of the cut.

\section{A Temporary VAT cut is like an Interest Rate Cut......}

When thinking about whether the temporary VAT cut will stimulate consumption in the current period, it is important to recognize that this temporary change reduces the 
price of consumption in the current period relative to the price of consumption next period. A cut in the interest rate would have the same effect on relative prices. These relative price changes can be illustrated with the inter-temporal budget constraint of a consumer with a 2 period planning horizon.

$$
W=c_{1}\left(1+t_{1}\right)+\frac{1}{1+r}\left(1+t_{2}\right) c_{2}
$$

$W$ is wealth, $c$ is consumption, $t$ is tax rate and $r$ is interest rate. Subscripts index periods. The price of consumption in period 1 is $\left(1+t_{1}\right)$ and the price of consumption in period 2 is $\frac{\left(1+t_{2}\right)}{1+r}$ so that the price of consumption in period 1 relative to that of consumption in period 2, is:

$$
\frac{p_{1}}{p_{2}}=\frac{\left(1+t_{1}\right)}{\left(1+t_{2}\right) /(1+r)}=\frac{\left(1+t_{1}\right)(1+r)}{\left(1+t_{2}\right)}
$$

An interest rate cut lowers this relative price, and so does a VAT cut in period 1. This change in relative prices induces a substitution effect: households will want to respond to the change in relative prices by substituting consumption out of the future and into the current period, since this has become cheaper.

Note that:

$$
\Delta \ln \left(\frac{p_{1}}{p_{2}}\right)=\Delta \ln \left(1+t_{1}\right)+\Delta \ln (1+r)-\Delta \ln \left(1+t_{2}\right)
$$

so that equal proportional changes in $\left(1+t_{1}\right)$ and $(1+r)$ have the same proportional impact on the relative price of consumption. This in turn implies that we can calculate the cut in the (real) interest rate, $\Delta r$, that has the same effect on the relative price of current consumption at a temporary cut in the VAT of $\Delta t=-1.275$ percentage points: 


$$
\Delta r=\frac{(1+r)}{(1+t)} \Delta t=\frac{(1+r)}{1.089}(-1.275)
$$

A reasonable approximation is that $\frac{(1+r)}{1.089} \approx 1$ so that the recently enacted temporary cut in VAT changes the relative price of current consumption by as much as (or perhaps a bit more than) a full percentage point (100 basis point) cut in interest rates. It is surprising that some commentators have labeled the former as "small”, while the latter would typically be considered a large cut.

\section{......but differs in important ways.}

A temporary VAT cut differs from an interest rate cut in several important ways. First, a temporary VAT cut flows to households via a different channel than an interest rate cut. An interest rate cut by the Bank of England lowers the cost of current consumption only if that cut is passed on by financial institutions to households. We would normally expect this to be the case, but in the current environment there is considerable evidence that lending is severely rationed, and lenders are not passing on Bank of England interest rate cuts in full to firms and households. Interest rate cuts by the Bank of England may be ineffective for this reason. For the VAT cut to have an impact, retailers must reduce their prices - the pass-through referred to above - but in the prevailing environment, this may be a more effective way of lowering the cost of current consumption than lowering interest rates.

Second, a temporary VAT cut has different implications for the public accounts than an interest rate cut. We return to revenue implications below. 
Third, a VAT cut is focused on household consumption. It will not have the same effect on investment by firms, or on the exchange rate (and hence exports) that an interest rate cut might.

Finally, a VAT cut and an interest rate cut have different income effects. We will discuss the magnitude of the income effect of a temporary VAT cut below but the sign is unambiguously positive: all consumers have increased purchasing power. By contrast, the income effect of an interest rate cut is positive only for borrowers, while it is negative for savers. Thus, roughly, the income effect of a temporary VAT cut is like that for an interest rate cut in an economy full of borrowers. This is illustrated in Figures 1, 2a, and 2b. Each Figure illustrates the case of a consumer with a 2 period horizon. Figure 1 illustrates a VAT cut in period 1. Figure 2a illustrates an interest rate cut for a saver (a consumer receiving income in period 1 only, and so saving for consumption in period 2). Figure $2 \mathrm{~b}$ illustrates an interest rate cut for a borrower (a consumer receiving income only in period 2 and so borrowing to consume in period 1). A temporary VAT cut has a positive income effect (Figure 1), analogous to an interest rate cut for borrowers (Figure $2 b)$.

\section{How large is the Substitution Effect?}

The relevant behavioral parameter is the elasticity of intertemporal substitution (eis). See Box 1 below. Attanasio and Wakefield (2008) survey micro-data based estimates of this parameter and suggest a "plausible range of values for the eis is between 0.5 and 1 ". The top of this range suggests a proportional consumption increase that is exactly equal to the proportional change in the price, so a $1.2 \%$ cut in the price of current 
consumption increases the level of consumption by $1.2 \%$. The intermediate case of an eis of 0.75 would equate to a $0.9 \%$ increase in current consumption.

There are at least two reasons to think that for the current application the relevant eis will be at the higher end of the range suggested by previous estimates. Both have to do with the fact that the VAT cut will fall on a different set of goods than the set of goods which economists have typically studied when estimating the eis. Micro-data estimates of the eis are based on total nondurable consumption - including VAT free goods like food, but excluding durables.

The first point to note is that the goods that do not face the full VAT rate are (mostly) necessities. As Browning and Crossley (2001) point out, "luxuries are easier to postpone”. The basic intuition is that necessities today are often not a good substitute for necessities tomorrow. For example, eating next month is not really a good substitute for eating this month; it is important to eat in both months. On the other hand, luxuries can probably be brought forward, or pushed back, in time, to take advantages of interest rates, or changes in the VAT rate. For example, a trip to Hawaii next month (or even next year) is probably a pretty good substitute for a trip to Hawaii this month. Thus it is reasonable to think that a household might postpone a trip to Hawaii when interest rates are very high (borrowing is costly and saving advantageous - the cost of current consumption is high) or bring a trip forward when interest rates are low (it is cheap to borrow, and saving offers little reward - the cost of current consumption is low). We would expect households to respond to a temporary VAT reduction in the same way.

A corollary of this point is that the rich, who consume many luxuries, will have a larger eis than the poor, who consume many necessities. This idea is developed further in 
Crossley and Low (2009) and in Box 2. This has implications for the distributional aspects of a VAT cut; we return to these below.

The second issue is durables. We expect durables to have a high eis for two reasons. First, many durables are also luxuries. Second, the durability of durables - or more precisely, their storability, breaks the link between expenditure and consumption. To a certain extent, the timing of expenditures on durables can be adjusted without altering the timing of consumption of service flows. This in turn means that expenditure should be highly responsive to intertemporal price differences.

To summarize, the basket of goods affected by a temporary VAT reduction has a higher eis than the basket of goods that is normally used to estimate the eis. The latter suggests an eis of perhaps 0.75 ; for the basket of goods affected by a temporary VAT cut, an elasticity of one does not seem unreasonable. Thus, as an assessment of the substitution effect of a 1.2\% fall in the price of current price of goods and services, an expenditure response of at least $1 \%$ seems a reasonable lower bound, and $1.2 \%$ is our preferred estimate.

Note with an eis of 1 , the increase in (real) consumption exactly offsets the fall in the price of current consumption, so that there is no change in current spending. This in turn implies no change in current saving, and hence no change in the resources available for future consumption.

Finally, if the government had announced that the revenue lost due to the temporary VAT reduction would be recouped through a higher future VAT, this would have increased the magnitude of the substitution effects discussed in this section. This is because the change in the tax rate in the future increases the size of the relative price 
change between the present and the future: in terms of equation [2], an increase in the denominator reinforces the reduction in the numerator. However, while the government apparently did consider increasing VAT to $18.5 \%$ in 2011, it ultimately chose instead to raise future revenues through different means (BBC News, 2008), as well as to cut spending.

\section{What about Income Effects and Credit Constraints?}

There are two reasons to think that the income effect of a temporary VAT reduction will be small. First, consumers have a longer planning horizon than two periods, and in this respect Figure 1 is misleading. A price cut for a good (current consumption) that is a small part of a consumers' basket (lifetime consumption) has a small income effect.

Second, if consumers anticipate that a temporary VAT cut will need to be paid for with higher taxes in the future, then the present value of their wealth is unchanged by the temporary VAT cut. This is the issue of Ricardian Equivalence. If consumers understand that the government has an intertemporal budget constraint, then the temporary VAT cut has no income effect.

These two considerations suggest that for unconstrained households the income effect must be small, and the substitution effect is the key behavioral response to the policy. There is a group, however, for whom this analysis is not correct. For those currently experiencing binding credit constraints, this analysis does not hold. This group would like to bring forward resources from the future in order to consumer more in the current period. For this group, the substitution effect is unimportant, and the temporary 
VAT cut has only an income effect. However, this income effect is easy to assess. As these consumers would like to consume more in the current period, they will increase consumption to offset completely the fall in prices, continuing to spend as much as they can. Thus a $1.2 \%$ fall in the price of current consumption induces a $1.2 \%$ increase in consumption.

In normal times, we would expect only a small fraction of UK consumers to be so credit constrained. However, in the current economic environment, the number of credit constrained consumers may be significantly greater. Conveniently, however, in this circumstance, the expected response of constrained and unconstrained consumers is of a similar magnitude, making the incidence of credit constraints largely immaterial for the macroeconomic question at hand.

\section{Revenue implications}

VAT revenue is $t \times c$ where $c$ is consumption (measured in pre-tax $£$ ). From this we can work out the proportional change in revenue for a given proportional change in the price of current consumption:

$$
\begin{aligned}
\frac{\ln R=\ln c+\ln t}{\partial \ln R} & =\frac{\partial \ln c}{\partial \ln (1+t)}+\frac{\partial \ln t}{\partial \ln (1+t)} \\
& =-e i s+\frac{t+1}{t} \\
& =-1+\frac{1.089}{0.089}=11.2
\end{aligned}
$$

Multiplying this by the $1.2 \%$ fall in the price of current consumption gives a short run fall in VAT revenue of $-13.4 \%$. The proportional change in revenue is less than the proportional change in the average tax rate (which as noted about is -14.3\%) because of 
the offsetting increase in current consumption. However, consumption is responding to the proportional change in its price $(\Delta \ln (1+t))$ which is much smaller than the proportional change in the tax rate $(\Delta \ln t)$. For this reason, even with an eis of 1 , the consumption response to the tax cut provides only very modest mitigation of the revenue loss. Since we expect no change in current saving, and hence in future consumption, future VAT revenues are unaffected by the temporary VAT cut. Future VAT revenues would be reduced if the consumption response to the temporary VAT cut was greater than one-for-one (that is, if the eis were greater than 1), so that households needed to finance some of the increase in current consumption through reductions in future consumption. Because we expect a slightly stronger expenditure response than the Treasury, we anticipate a slightly smaller cost for the stimulus (on current figures, VAT raises $£ 82.6$ billion annually, or $£ 93.4$ billion in 13 months. The Treasury costed the temporary VAT cut at $£ 12.4$ Billion or $13.9 \%$ of revenue.)

\section{Distributional Consequences}

The goods that are VAT exempt or face a reduced VAT rate (and hence are unaffected by the temporary VAT cut) are largely necessities. Thus VAT is actually a slightly progressive tax, and the temporary VAT cut slightly regressive: the cut confers greater (proportional) benefits on the rich (who consume more luxuries) than the poor.

This is illustrated in Figure 3, which shows that households with higher total expenditures (that is, richer households) derive a higher proportional benefit from the VAT cut.

The calculations presented in Figure 3 assume no behavioral response, but we have argued above that the temporary VAT cut should induce a substitution effect. 
Allowing for this substitution effect reinforces the mildly regressive nature of the VAT cut. Because luxuries have a larger eis, the rich not only face a larger average price cut on their basket of goods, but also are more inclined to take advantage of the temporary price cut by bringing forward consumption. These two considerations both imply that the temporary VAT cut benefits the rich more than the poor.

\section{Importance of the Counterfactual}

It is important to emphasize that that the predictions outlined in the preceding sections are relative to the counterfactual of no policy change. An increase of $1.2 \%$ against a counterfactual of falling consumption may translate into a reduced fall, rather than an actual rise. In the current environment, there may be a number of coincident effects that will mask the effect of the policy. If deflationary expectations are taking hold, these will reduce the expected relative price of future consumption, thus inducing a substitution effect in the opposite direction of the policy. Further, significant increases in uncertainty may make household feel less affluent, inducing a negative income effect which is, again, in the opposite direction to the policy. The increase in uncertainty may be particularly relevant to expenditure on durables. To the extent that expenditure on durables is irreversible, there is an option value associated with waiting, which may suppress expenditure on durables until some of the current uncertainty resolves.

\section{Bottom Line}

For forward looking and unconstrained consumers, we would expect the income effect of a temporary cut in VAT to be small, and the substitution effect to be relatively 
important. We believe that the eis for affected goods is around one, so that, for unconstrained households, a response to the $1.2 \%$ price fall of an increase of around $1.2 \%$ in current (real) consumption seems reasonable. For constrained households, the mechanism is quite different, but the outcome is the same, a response of about $1.2 \%$ in current (real) consumption. Thus the overall response does not depend significantly on the incidence of credit constraints in the economy and we should expect a response of about $1.2 \%$ in current (real) consumption. This is significantly larger than the Treasury's prediction (summarized above). Further, given that prices are falling by a similar amount to the increase in consumption, we should expect little change in nominal expenditures, which in turn means no increase in saving (in contrast to what the Treasury suggests.) This analysis suggests a short run fall in revenue from the VAT of about 13\%. Finally, the rich will benefit somewhat more from this rate cut than the poor.

\section{Two Caveats}

As the proceeding discussion indicated, there are two important areas where we lack evidence to inform our analysis of the economic effects of a temporary VAT cut.

The first has to do with the extent of pass-through. Some commentators have suggested that pass-through will be limited, so that the retail prices will be little affected by the VAT cut. The argument that is usually advanced has to do with "menu costs." It is argued that there is a cost associated with changing retail prices, that this cost is borne by firms, and that the tax cut is too small for retailers to bother with changing prices. We think that this argument is probably mistaken. Technological innovations have reduced the menu costs associated with price changes dramatically in recent years; for online retailers, as well as for large retailers like Tesco employing the latest technology for 
pricing and inventory management, menu costs are essentially zero. Such retailers account for a very large fraction of retail sales: Moreover, in the current environment, retailers are very anxious to generate sales, and anecdotal evidence suggests that retailers are not only passing-through the VAT cut, but are also actively promoting consumer awareness of the fall in the price of current consumption (see Figure 4). Nevertheless, it is true that we lack formal evidence to guide our expectations about pass-through, and this would be a useful question for future research to address.

The second area in which evidence is lacking is the responsiveness of spending on durables to changes in the price of durables today (relative to the price of the durables in the future.) As we noted above, most estimates of the eis are based on nondurable consumption, but durables may be an important component of the response of current spending to a change in relative prices. There are two issues here: first, the storability of durables means that their substitutability over time in expenditure may be greater than for goods that are non-storable. Second, we normally think of the nondurable eis as being a preference parameter (and so, roughly, invariant to amount of uncertainty in the economic environment). However, because of the irreversible nature of many durable purchases, they are, as indicated above, quite sensitive to economic uncertainty, and it may be that uncertainty not only suppresses the level of durables demand but also diminishes the responsiveness of durables demand to changes in relative prices (whether those relative price changes are brought about by a cut to the VAT rate, or by a cut to the interest rate.) This is another area in which more research is needed. 


\section{References}

Adam, S., and J. Browne, (2006), “A Survey of the UK tax system,” IFS Briefing Note 9, http://www.ifs.org.uk/bns/bn09.pdf.

Adam, S., (2008), “Indirect and Business Taxes,” IFS Briefing on the Pre-Budget Report 2008 http://www.ifs.org.uk/budgets/pbr2008/index.php

Attanasio, Orazio and Matthew Wakefield, (2008), “The Effects on Consumption and Saving of Taxing Asset Returns,” Prepared for the Report of a Commission on Reforming the Tax System for the 21st Century, Chaired by Sir James Mirrlees. http://www.ifs.org.uk/mirrleesreview/reports/consumption.pdf

BBC News Online, (2008), “Treasury Eyed VAT Rise to 18.5\%,” Tuesday, November $25^{\text {th }}, 2008$. http://news.bbc.co.uk/1/hi/business/7749074.stm

Browning, M. and T.F. Crossley. "Luxuries are Easier to Postpone: A Proof." Journal of Political Economy. 108(5):1064-1068. (October, 2000.)

Crossley, T.F. and H. Low, (2009) "Is the Elasticity of Inter-temporal Substitution Constant?"

HM Treasury (2008), Pre-Budget Report November 2008: Facing global challenges: Supporting people through difficult times, Cm 7484, London: The Stationery Office (http://www.hm-treasury.gov.uk/prebud_pbr08_repindex.htm). 


\section{BOX 1: The Approximate Euler Equation}

It is often assumed that utility is additive over time, and that utility in any period is a power function of the level of consumption in a period:

$$
u\left(c_{t}\right)=\frac{c_{t}^{1-(1 / \theta)}}{1-(1 / \theta)}
$$

This common variant of the LC/PIH has household maximize:

$$
E\left[\sum_{t=1}^{T} \beta^{t} u\left(c_{t}\right)\right]=E\left[\sum_{t=1}^{T} \beta^{t} \frac{c_{t}^{1-(1 / \theta)}}{1-(1 / \theta)}\right]
$$

With this set up one can show the following approximate relationship:

$$
\Delta \ln c_{t+1}=\alpha+\theta \ln \left(1+r_{t+1}\right)+u_{t+1}
$$

Here $\theta>0$ is the elasticity of intertemporal substitution. It measures the effect of the rate of return $\left(r_{t+1}\right)$ on the rate of consumption growth $\left(\Delta \ln c_{t+1}\right)$. For a given $\theta$, when $r_{t+1}$ is larger, consumption growth is larger, meaning more saving today, and more spending in the future. For a given increase in $r_{t+1}$ (through, for example, reducing taxes on interest income), a larger $\theta$ means a larger increase in consumption growth (meaning more saving today, and more spending in the future.) 


\section{BOX 2: The Approximate Euler Equation with Subsistence Consumption}

One way to think about the intuition for why the EIS is higher for the rich is to modify the model in BOX 1 just slightly, and make the (not unreasonable) assumption that utility depends on the excess of consumption over a subsistence amount $\underline{c}$ :

$$
u\left(c_{t}\right)=\frac{\left(c_{t}-\underline{c}\right)^{1-(1 / \theta)}}{1-(1 / \theta)}
$$

A subsistence level of consumption captures the idea that some components of consumption are very difficult to postpone or bring forward (the subsistence amount must be consumed in every period) as well as the suggestion that those components of consumption are more important for poorer households. With this modified model one can show that the approximate relationship between rates of return an consumption growth becomes:

$$
\Delta \ln c_{t+1}=\alpha+\left(\frac{c_{t}-\underline{c}}{c_{t}}\right) \theta \ln \left(1+r_{t+1}\right)+u_{t+1}
$$

And the elasticity of intertemporal substitution is now $\left(\frac{c_{t}-\underline{c}}{c_{t}}\right) \theta$ which differs between rich and poor and in particular is larger for the rich. In this setup the interest rate responses of rich or middle class families are different from the interest rate responses of poor families, and in particular, as $c$ gets close $\underline{c}$ (that is, for households close to the minimum subsistence level they need to survive and function in society) households cease to substitute (whether the change in the relative price of current consumption comes from an interest rate change or a temporary VAT cut.) 
$\mathrm{C}_{2}$

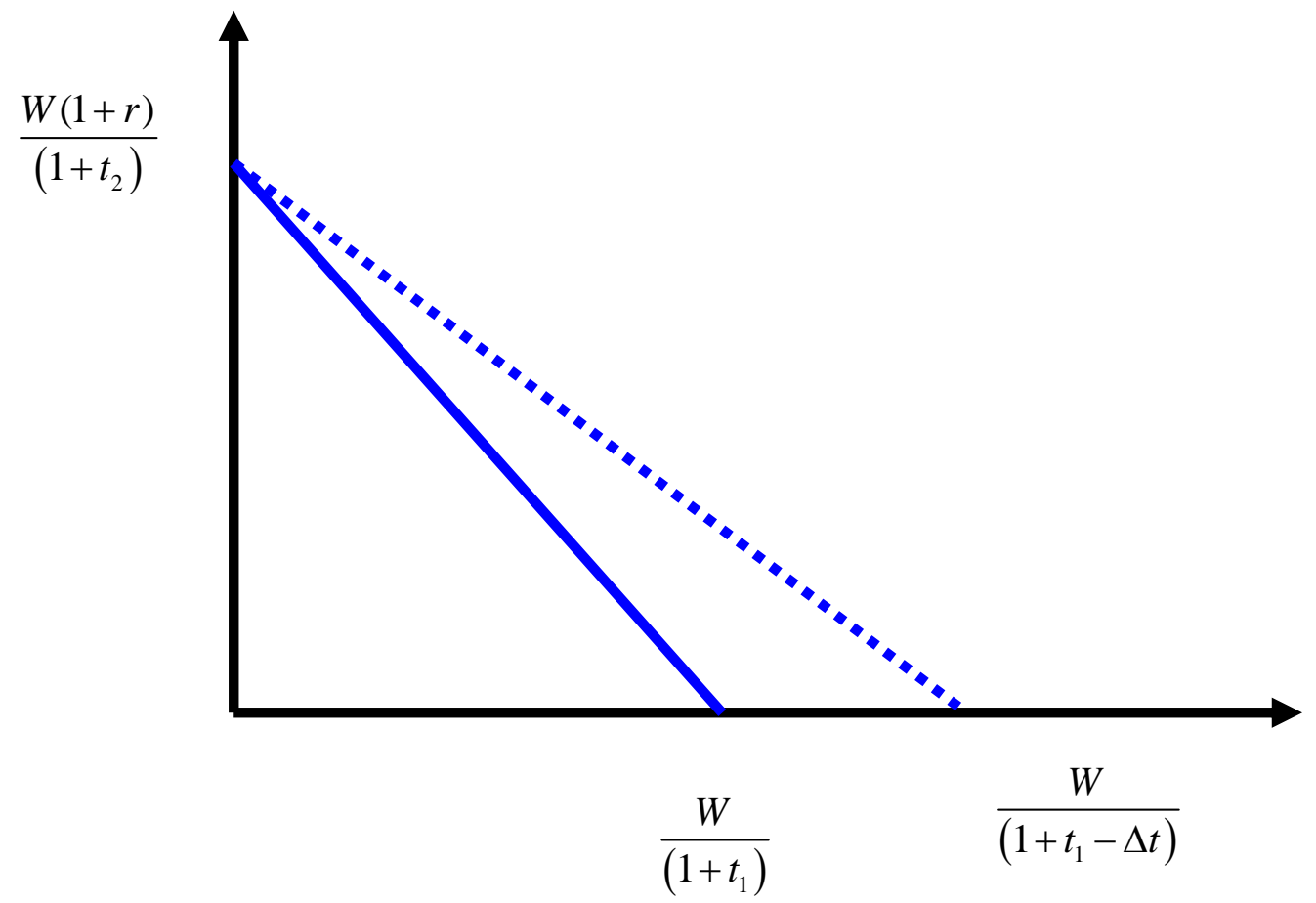

$\mathrm{C}_{1}$

Figure 1: Period 1 VAT cut in a 2-period Model 
$\mathrm{C}_{2}$

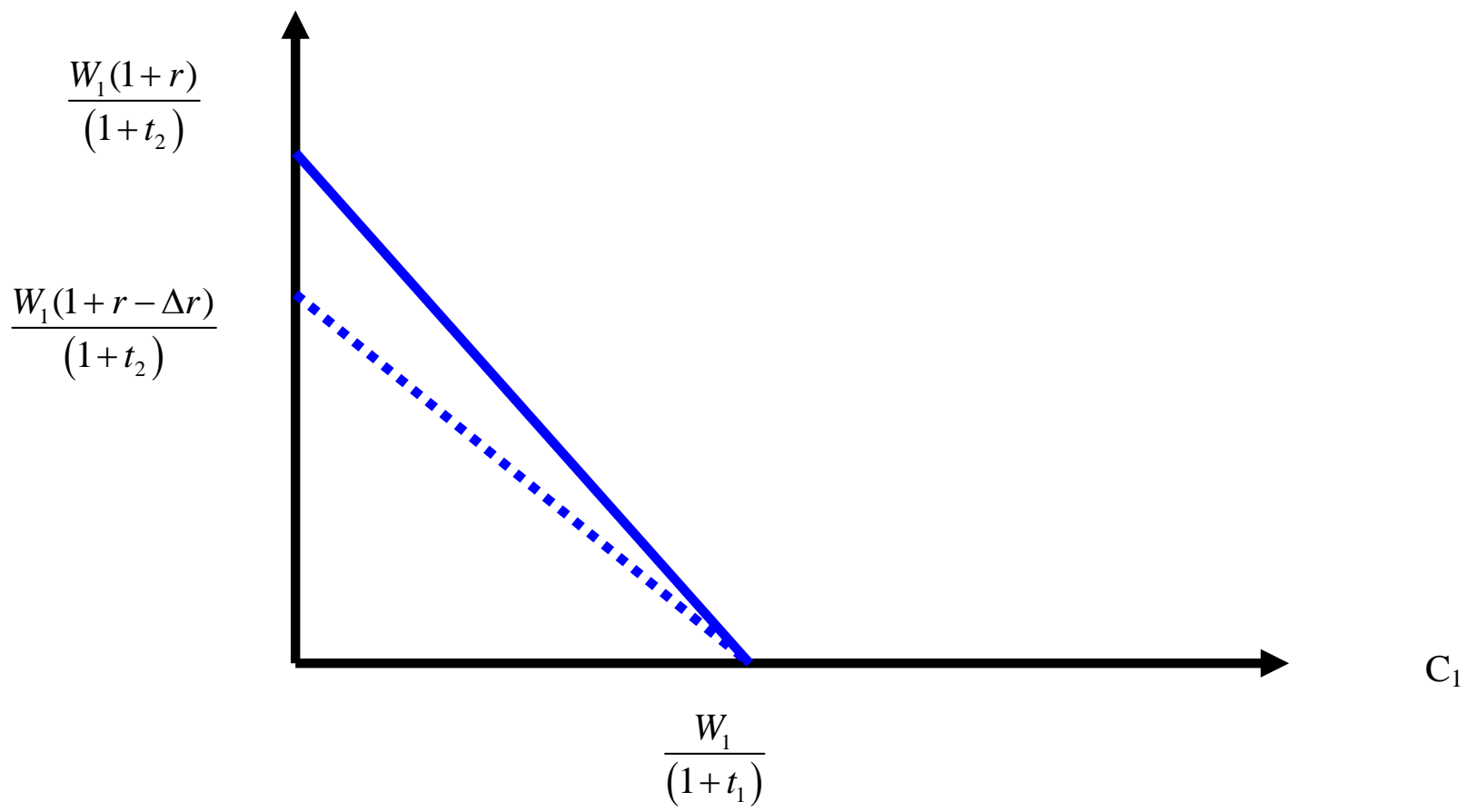

Fioure 2(a): Interest rate cut in a 2-period model - Saver (income in period 1 only) $\mathrm{C}_{2}$

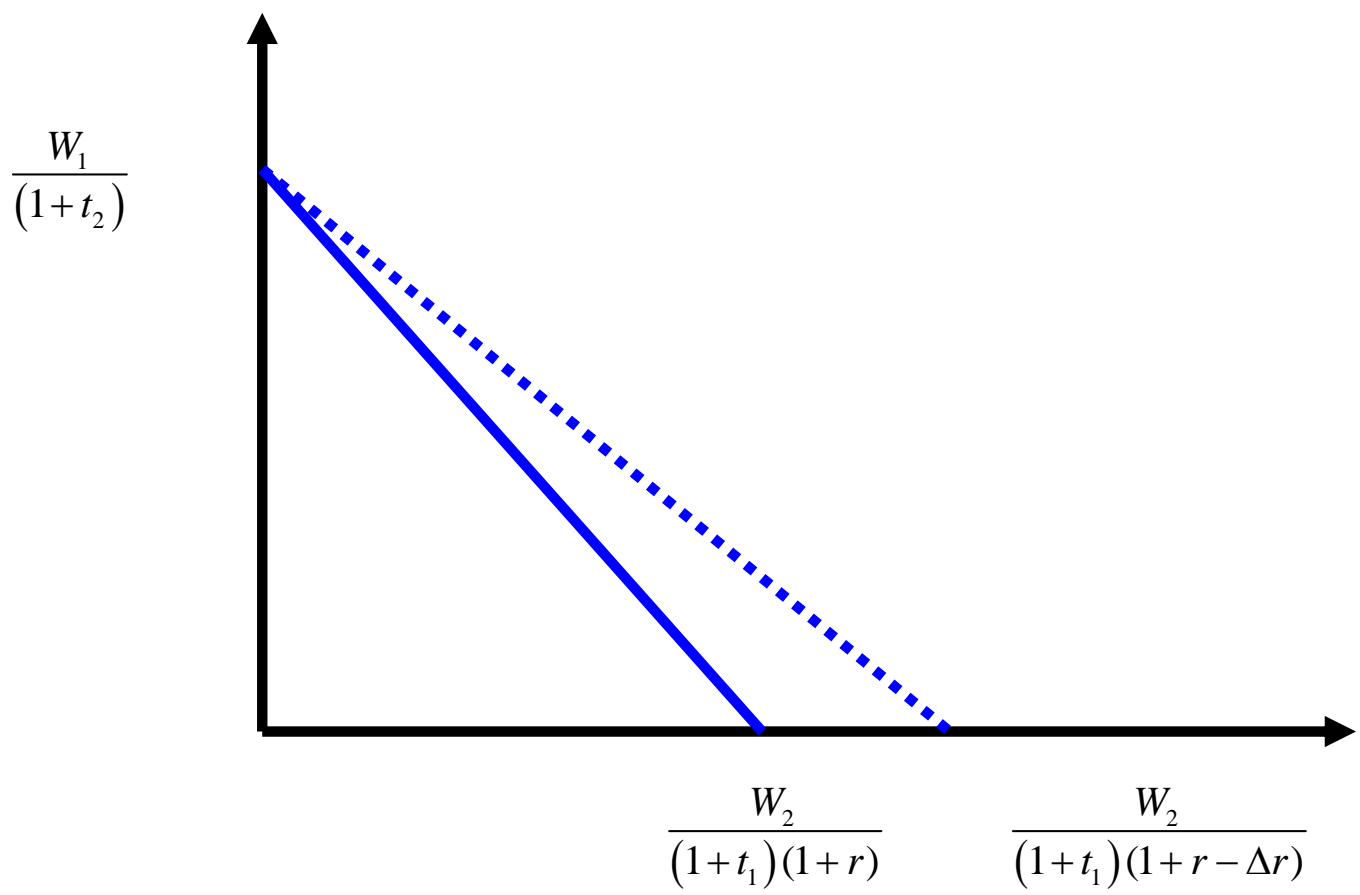

$\mathrm{C}_{1}$

Figure 2(b): Interest rate cut in a 2-period model - Borrower (income in period 2 only) 


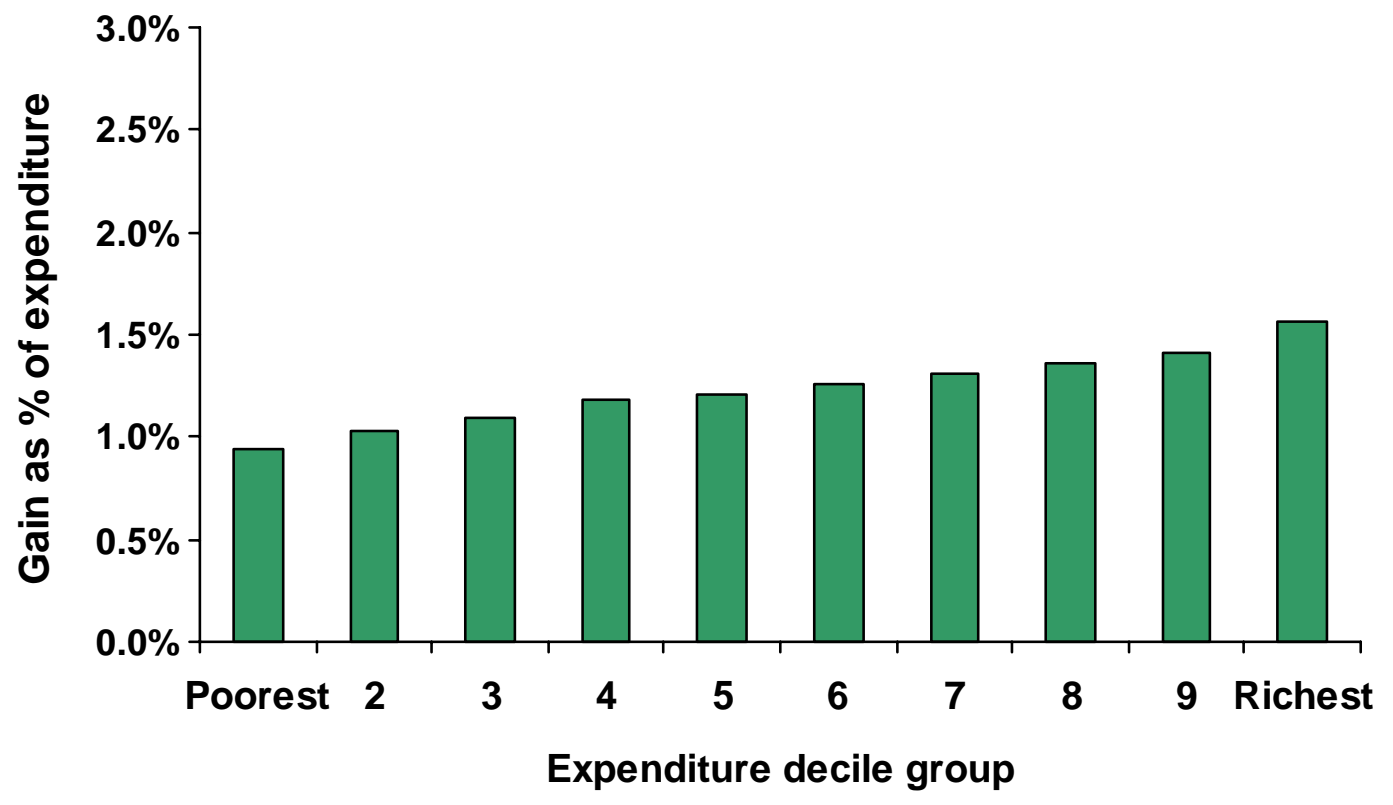

Figure 3. Gain from temporary VAT cut and Duty Changes by expenditure decile Source: Adams (2008) 


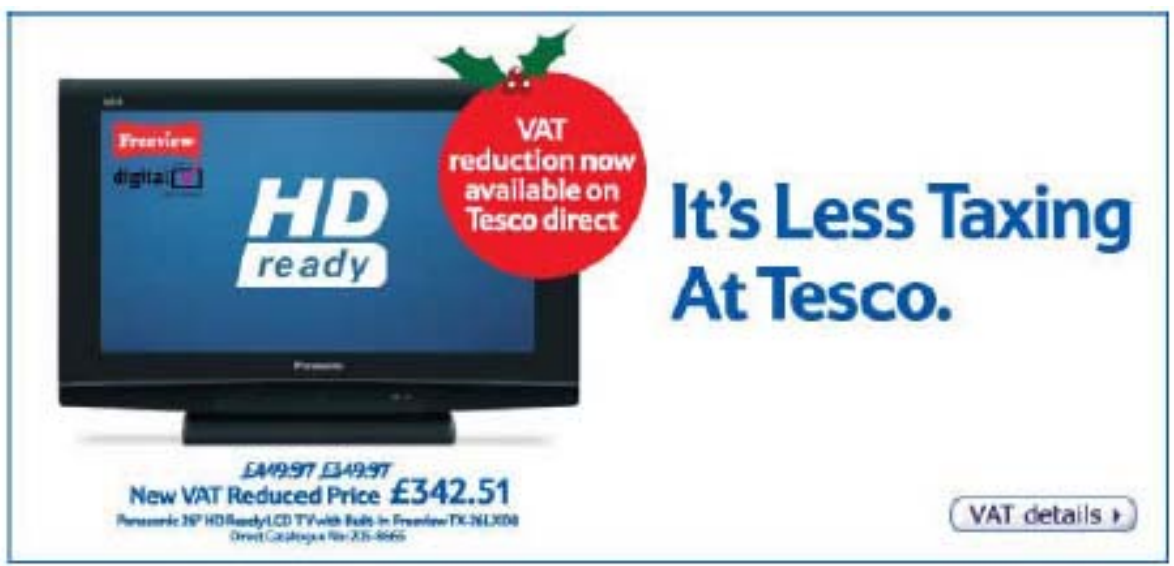

Figure 4: Tesco Promotes the Government's Fiscal Stimulus. Source:www.tesco.com December $3^{\text {rd }}$, 2008 